\title{
Neuro-imaging of mindfulness meditations: implications for clinical practice
}

Submitted 18 October 2010; revised 15 January 2011; accepted 17 January 2011

\section{Dear Editor}

Scientific research has long attempted to uncover the neurobiological correlates of psychiatric diseases so as to elucidate existing differences between individuals affected by psychiatric disorders and healthy subjects (e.g. Bellani, Marzi \& Brambilla, 2009; Bellani, Baiano \& Brambilla, 2010). However, it is less clear so far as to which are the effects on the brain of specific mental trainings devoted to the development of higher emotional and cognitive skills such as meditation. Mindfulness meditations (MM), including, among the others, ancient Buddhist meditations such as Vipassana (or Insight meditation) and Zen meditation as well as recent clinically oriented interventions such as Mindfulness-based Stress Reduction (MBSR) and Mindfulness-based Cognitive Therapy (MBCT), are a subgroup of meditation practices that are recently receiving growing attention both for their potential clinical applications and the insights into the functioning of healthy human mind (Chiesa \& Serretti, 2010).

Of note, important differences exist across different MM into the way mindfulness is understood and practised [for a detailed description, see Chiesa \& Malinowski (2010)]. Main differences across such interventions include the extensive concentrative meditation training and the importance of an ethical development required by most ancient Buddhist $\mathrm{MM}$ on the one hand and the introduction of specific psychological exercises mainly drawn from clinical cognitivism in some of the recently developed MM such as MBCT on the other. In addition, ancient MM are mainly aimed at developing a correct balance between the mental stability developed by concentrative practices and mental clarity deriving from mindfulness practice as a means to develop a reflexive awareness that grants one greater access to the rich features of each experience, leading to a higher ability to discriminate between wholesome and unwholesome emotions as well as their triggers and consequences. This, in turn, is supposed to help the practitioner to increasingly emphasize the former and

* Address for correspondence: A. Chiesa, Institute of Psychiatry, University of Bologna, Viale Carlo Pepoli 5, 40123 Bologna, Italy.

(Email: alberto.chiesa@yahoo.it) decrease the latter ones. On the other hand, MBSR and MBCT reject the idea of mindfulness having goals that the practitioner strives towards, and consequently nonjudgmental awareness of the present moment is seen as the essence and the final aim of practice. However, it is worth mentioning that all such practices do not differ with regard to the most fundamental features that include, first, the development of a mental state characterized by full attention to internal and external experiences as they occur in any given moment and, second, a particular attitude characterized by non-judgment of, and openness to, current experience (Chiesa \& Malinowski, 2010). Accordingly, one could expect that both brain areas involved in attention and those involved in emotions and emotional regulation could be involved in mindfulness training. The aim of the present paper is therefore to review available evidence concerning recent findings of functional and structural neuro-imaging studies in mindfulness meditators.

A literature research was independently undertaken by the reviewers using MEDLINE, ISI web of science, EMBASE, PsychINFO and references of retrieved articles. The search included papers indexed by webbased electronic databases mentioned above published up to October 2010. The search strategy considered only studies published in English. The main search terms were MBSR, MBCT, Vipassana and Zen meditation in combination with (functional) magnetic resonance imaging ((f)MRI), positron emission tomography (PET), single-photon emission computed tomography (SPECT), functional neuro-imaging and structural neuro-imaging. Included studies had to: (1) focus on one of the meditation practices mentioned above, (2) provide information about the neural correlates of such meditation practices and (3) provide quantitative data supported by adequate statistical methodology. Excluded were: (1) qualitative and speculative reports, (2) articles providing information about MM other than that mentioned above (e.g. clinical and psychological correlates of $\mathrm{MM}$ ) and (3) reviews and meta-analysis. Taking into account the novelty of the field, both controlled and uncontrolled studies were included.

Following the application of inclusion and exclusion criteria, 13 studies could be included in the present 
review (Table 1). Seven focused on the functional neuro-imaging correlates of MM, whereas six focused on the structural neuro-imaging correlates. The large majority of available data compared meditators with varying degree of expertise with a meditation-naïve control group and relied on traditional Buddhist meditation practices, probably because many of these studies aim at investigating cognitive abilities at the extreme end, for which only experienced meditators of established traditions are currently viable participants.

In particular, current studies focusing on functional correlates of long-term Vipassana and Zen meditators found increased activation of two major areas of the prefrontal cortex (PFC), the ventromedial PFC (vmPFC) and the dorsolateral PFC (dlPFC) and of the anterior cingulate cortex (ACC) during meditation as compared with simple rest and arithmetic conditions or with matched control subjects naïve to meditation practice (Baerentsen et al. 2001; Hölzel et al. 2007; Kozasa et al. 2008). In addition, a reduced duration of the neural response linked to conceptual processing in regions of the default network was observed in a sample of Zen meditators compared with a meditation naïve control group during a task involving mindfulness of breathing while reading distracting words (Pagnoni, Cekic \& Guo, 2008). On the basis of such observation, the authors suggested that MM training could foster the ability to voluntary regulate the flow of spontaneous meditation (Pagnoni, Cekic \& Guo, 2008). In addition, as the rostral/ventral division of the ACC and the MPFC are activated in emotional processing, some authors have hypothesized that MM training could lead to a more cortical processing of emotional conflicts and processes during meditation whereby such areas could exert an inhibitory effect on limbic regions through inhibitory connections from the orbitofrontal cortex, possibly reflecting an improved ability for emotional regulation (e.g. Chiesa, Brambilla \& Serretti, 2010).

A critical look at this research, however, reveals important methodological weaknesses. As these studies are cross-sectional, they do not allow to infer causality as to whether observed differences actually result from meditation practice. Interpreting these differences is furthermore limited by the fact that meditation and control groups are often insufficiently matched and, for instance, differ with regard to sociocultural background or lifestyle or could differ with regard to overall intelligence levels, as this variable has never been assessed.

More recent prospective randomized controlled trials focusing on short-term MM programs tend not to suffer from such limitations and can provide more reliable data. Interestingly, such studies support the notion that MM practice could be associated with a higher activation of the PFC and ACC in subjects addressed to MBSR during mindful attention to the breath but not during a narrative focus as compared with those addressed to a waiting list (Farb et al. 2007). Furthermore they suggest that, when focusing on present moment experience, meditators who have completed the MBSR program differ from controls in that they more easily engage the right dIPFC, an area associated with a more detached observation state of events characterized by lower emotional reactivity (Farb et al. 2007), and that they develop an enhanced ability to balance affective and sensory neural networks leading to reduced vulnerability to dysphoric reactivity (Farb et al. 2010). Consonant with such explanation is the observation that even short-term MM training was found to be associated with reduced amygdala activation in response to negative stimuli (Farb et al. 2007; Goldin \& Gross, 2010).

Intriguingly, structural neuro-imaging studies consistently support such findings. As an example, both thicker ACC (Grant et al. 2010) and reduced amygdala grey matter density (Hölzel et al. 2010) have been observed in expert mindfulness meditators as compared with matched controls and in subjects randomly addressed to MBSR as compared with those addressed to a waiting list. Of further interest, in long-term mindfulness meditators several areas related to viscerosomatic awareness such as the insula were thicker in comparison with controls (Lazar et al. 2005; Hölzel et al. 2008; Grant et al. 2010), presumably reflecting the specific training during $\mathrm{MM}$, namely the awareness of bodily sensations. Also, further evidence suggests that MM might offer protection from cognitive decline through inhibition of the reduction both in grey matter volume and attentional performance usually associated with age (Pagnoni \& Cekic, 2007).

As one can observe from this brief overview, most consistent findings converge on identifying a higher activation of the PFC, particularly right dlPFC and of the rostral/ventral division of the ACC as well as a reduced amygdala activation as important features of MM. Intriguingly, the similarities between areas activated in functional neuro-imaging studies and those observed to be thicker in structural ones (in particular thicker ACC and reduced amygdala grey matter density) suggest the hypothesis that repeated activation (or deactivation) of specific brain areas could lead to long-lasting brain structure changes (e.g. Lazar et al. 2005; Hölzel et al. 2008; Grant et al. 2010). However, further research based on more rigorous long-term prospective studies is needed to better explore such an issue.

Overall, such findings, along with evidence deriving from clinical studies, preliminary support the notion 
Table 1. Functional and structural neuro-imaging studies of MM

\begin{tabular}{|c|c|c|c|c|c|}
\hline Study & $\begin{array}{l}\text { Study } \\
\text { design }\end{array}$ & $\begin{array}{l}\text { Study } \\
\text { duration }\end{array}$ & Subjects & $\begin{array}{l}\text { Type of imaging and } \\
\text { task }\end{array}$ & Main findings \\
\hline \multicolumn{6}{|c|}{ Functional neuro-imaging findings } \\
\hline Baerentsen et al. (2001) & $\begin{array}{l}\text { CSS } \\
\text { without } \\
\text { controls }\end{array}$ & n.a. & $\begin{array}{l}\text { Five long-term Zen } \\
\text { meditators with } 7- \\
23 \text { years of practice }\end{array}$ & $\begin{array}{l}\text { fMRI, onset of } \\
\text { meditation }\end{array}$ & $\begin{array}{l}\text { Increased activation of the } \\
\text { PFC, ACC and } \\
\text { hippocampus, decreased } \\
\text { activation of PCC and } \\
\text { visual cortex }\end{array}$ \\
\hline Farb et al. (2007) & $\mathrm{RCT}$ & 8 weeks & $\begin{array}{l}\text { Thirty-six novice } \\
\text { meditators } \\
\text { randomly assigned } \\
\text { to MBSR }(n=20) \text { or } \\
\text { to waiting list } \\
(n=16)\end{array}$ & $\begin{array}{l}\text { fMRI, narrative } v \text {. } \\
\text { experiential focus } \\
\text { (EF) }\end{array}$ & $\begin{array}{l}\text { During EF, meditators } \\
\text { showed increased R } \\
\text { dlPFC, R ilPFC, R insula } \\
\text { and somatosensory cortex } \\
\text { activation and decreased } \\
\text { amygdala activation, } \\
\text { whereas non-meditators } \\
\text { showed increased L vlPFC } \\
\text { and L dlPFC }\end{array}$ \\
\hline Hölzel et al. (2007) & $\begin{array}{l}\text { CSS with } \\
\text { controls }\end{array}$ & n.a. & $\begin{array}{l}\text { Fifteen long-term } \\
\text { Vipassana } \\
\text { meditators with } \\
7.9 \pm 5.1 \text { years of } \\
\text { practice and } 15 \\
\text { controls }\end{array}$ & $\begin{array}{l}\text { fMRI, meditation } \\
\text { and arithmetic } \\
\text { condition }\end{array}$ & $\begin{array}{l}\text { Increased dmPFC and rostral } \\
\text { ACC activation in } \\
\text { meditators over controls }\end{array}$ \\
\hline $\begin{array}{l}\text { Pagnoni, Cekic \& Guo } \\
\text { (2008) }\end{array}$ & $\begin{array}{l}\text { CSS with } \\
\text { controls }\end{array}$ & n.a. & $\begin{array}{l}\text { Twelve long-term } \\
\text { Zen meditators } \\
\text { with } 3 \text { or more } \\
\text { years of practice } \\
\text { and } 12 \text { controls }\end{array}$ & $\begin{array}{l}\text { fMRI, mindfulness of } \\
\text { breathing while } \\
\text { distracting by } \\
\text { words }\end{array}$ & $\begin{array}{l}\text { L language areas (including } \\
\text { angular gyrus and } \\
\text { superior frontal gyrus) } \\
\text { activated for less time after } \\
\text { words distraction in } \\
\text { meditators than controls }\end{array}$ \\
\hline Kozasa et al. (2008) & UPT & 8 days & $\begin{array}{l}\text { Five Zen meditators } \\
\text { with } 6 \text { months or } \\
\text { more of practice } \\
\text { after a retreat }\end{array}$ & fMRI, Stroop effect & $\begin{array}{l}\text { Increased R dlPFC, ACC, } \\
\text { insula and parietal cortex }\end{array}$ \\
\hline Farb et al. (2010) & $\mathrm{RCT}$ & 8 weeks & $\begin{array}{l}\text { Thirty-six novice } \\
\text { meditators } \\
\text { randomly assigned } \\
\text { to MBSR }(n=20) \text { or } \\
\text { to waiting list } \\
(n=16)\end{array}$ & $\begin{array}{l}\text { fMRI, vision of } \\
\text { neutral and sad } \\
\text { clips }\end{array}$ & $\begin{array}{l}\text { Higher } \mathrm{R} \text { lateralized } \\
\text { recruitment including } \\
\text { visceral and somatosensory } \\
\text { areas in meditators } \\
\text { correlated with decreased } \\
\text { depression scores in } \\
\text { response to sad clips }\end{array}$ \\
\hline Goldin \& Gross (2010) & UPT & 8 weeks & $\begin{array}{l}\text { Sixteen novice } \\
\text { meditators with } \\
\text { SAD addressed } \\
\text { to MBSR }\end{array}$ & $\begin{array}{l}\text { fMRI, reaction of } \\
\text { negative beliefs } \\
\text { during } \\
\text { mindfulness } v \text {. } \\
\text { distraction focus }\end{array}$ & $\begin{array}{l}\text { During mindfulness but not } \\
\text { distraction condition, } \\
\text { subjects displayed reduced } \\
\text { amygdala and midline } \\
\text { cortical activation as well as } \\
\text { increased parietal and } \\
\text { occipital activation }\end{array}$ \\
\hline \multicolumn{6}{|c|}{ Structural neuro-imaging findings } \\
\hline Lazar et al. (2005) & $\begin{array}{l}\text { CSS with } \\
\text { controls }\end{array}$ & n.a. & $\begin{array}{l}\text { Twenty long-term } \\
\text { Vipassana } \\
\text { meditators with } \\
9.1 \pm 7.1 \text { years of } \\
\text { practice and } 15 \\
\text { controls }\end{array}$ & MRI, resting state & $\begin{array}{l}\text { Brain regions associated with } \\
\text { attention, interoception } \\
\text { and sensory processing, } \\
\text { including the middle and } \\
\text { superior frontal gyri and } \\
\text { right anterior insula were } \\
\text { thicker in meditators than } \\
\text { matched controls }\end{array}$ \\
\hline
\end{tabular}


Table 1. Continued

\begin{tabular}{|c|c|c|c|c|c|}
\hline Study & $\begin{array}{l}\text { Study } \\
\text { design }\end{array}$ & $\begin{array}{l}\text { Study } \\
\text { duration }\end{array}$ & Subjects & $\begin{array}{l}\text { Type of imaging and } \\
\text { task }\end{array}$ & Main findings \\
\hline $\begin{array}{l}\text { Pagnoni \& Cekic } \\
\quad(2007)\end{array}$ & $\begin{array}{l}\text { CSS with } \\
\text { controls }\end{array}$ & n.a. & $\begin{array}{l}\text { Thirteen expert Zen } \\
\text { meditators more } \\
\text { than } 3 \text { years of } \\
\text { practice and } 13 \\
\text { matched controls }\end{array}$ & MRI, resting state & $\begin{array}{l}\text { Control subjects displayed } \\
\text { the expected negative } \\
\text { correlation of both grey } \\
\text { matter volume and } \\
\text { attentional performance } \\
\text { with age; meditators did } \\
\text { not show a significant } \\
\text { correlation of either } \\
\text { measure with age. The } \\
\text { effect was most prominent } \\
\text { in the putamen }\end{array}$ \\
\hline Hölzel et al. (2008) & $\begin{array}{l}\text { CSS with } \\
\text { controls }\end{array}$ & n.a. & $\begin{array}{l}\text { Twenty long-term } \\
\text { Vipassana } \\
\text { meditators with } \\
8.6 \pm 5 \text { years of } \\
\text { practice and } 20 \\
\text { controls }\end{array}$ & MRI, resting state & $\begin{array}{l}\text { Greater grey matter } \\
\text { concentration for } \\
\text { meditators in the } \mathrm{R} \\
\text { anterior insula and } \mathrm{R} \\
\text { hippocampus. }\end{array}$ \\
\hline $\begin{array}{l}\text { Vestergaard-Poulsen } \\
\text { et al. (2009) }\end{array}$ & $\begin{array}{l}\text { CSS with } \\
\text { controls }\end{array}$ & n.a. & $\begin{array}{l}\text { Ten long-term Zen } \\
\text { meditators with } \\
\text { 14-31 years of } \\
\text { practice and } 10 \\
\text { controls }\end{array}$ & MRI, resting state & $\begin{array}{l}\text { Increased grey matter } \\
\text { density in the brainstem, } \\
\text { especially in the medulla } \\
\text { oblongata }\end{array}$ \\
\hline Holzel et al. (2010) & UPT & 8 & $\begin{array}{l}\text { Twenty-six novice } \\
\text { meditators } \\
\text { addressed to } \\
\text { MBSR }\end{array}$ & MRI, resting state & $\begin{array}{l}\text { Following MBSR, reduced } \\
\text { perceived stress was } \\
\text { correlated with reduced } \mathrm{R} \\
\text { basolateral amygdala grey } \\
\text { matter density }\end{array}$ \\
\hline Grant et al. (2010) & $\begin{array}{l}\text { CSS with } \\
\text { controls }\end{array}$ & n.a. & $\begin{array}{l}\text { Seventeen long-term } \\
\text { Zen meditators } \\
\text { with }>1000 \mathrm{~h} \text { of } \\
\text { practice and } 18 \\
\text { controls }\end{array}$ & MRI, resting state & $\begin{array}{l}\text { Meditators had thicker } \\
\text { cortex in the dorsal ACC } \\
\text { and in secondary } \\
\text { somatosensory cortex than } \\
\text { controls }\end{array}$ \\
\hline
\end{tabular}

CSS, cross-sectional study; RCT, randomized controlled trial, UPT, uncontrolled prospective trial; (f)MRI, (functional) magnetic resonance imaging; ACC, anterior cingulated cortex; PFC, prefrontal cortex; PCC, posterior cingulated cortex; dlPFC, dorsolateral prefrontal cortex; ilPFC, inferolateral prefrontal cortex; vlPFC, ventrolateral prefrontal cortex; dmPFC, dorsomedial prefrontal cortex; L and R before other words mean left and right, respectively and n.a., not applicable.

that MM practice could be related to significant changes in brain structures/patterns of activation associated with higher bodily awareness and attentional performances as well as with lower emotional reactivity, two issues that may have important clinical implications. As an example, sustained increased limbic activity and decreased pre-frontal activity have frequently been observed in patients with emotional disorders such as major depression and anxiety disorders (DeRubeis, Siegle \& Hollon, 2008), which are supposed to be characterized by a deficit in one's own emotional regulation strategy. Although there is some disagreement as to whether operationalizations of emotional regulation should be restricted to conscious, explicit processes or whether they should include both conscious and unconscious (implicit) processes, there is currently substantial agreement that at least some forms of emotional regulation do not require conscious control. In addition, some have suggested that repeated activation of conscious emotional regulation strategies in response to particular stimuli could, over time, lead to that strategy being employed automatically and non-consciously. In an attempt to explain how mindfulness works at the level of the psychological processes involved, Chambers et al. have recently put forth that mindfulness can be described as an emotional regulation strategy distinct from other types of emotional regulation considered so far, which is characterized by a systematic retraining of awareness, which allows the 
individual for a more conscious choice of thoughts, emotions and sensations with which one could identify, rather than automatically reacting to them (Chambers, Gullone \& Allen, 2009). In accordance with such view, mindfulness could be considered as an explicit emotional regulation strategy that stands at the opposite of usual reactive patterns of emotion expression and experience characterized by processes such as rumination, emotional suppression and avoidance. Interestingly, in line with such view, it is noteworthy that an increasing number of clinical studies are providing evidence about the usefulness of $\mathrm{MM}$ for a great variety of psychiatric conditions characterized by a deficit in emotional regulation strategies (Chiesa \& Serretti, 2010).

As a further example, several disorders exist that are characterized by a deficit or a progressive loss of neuropsychological functions such as attention, including attention deficit/hyperactive disorders (ADHD) in children and several types of dementia in the elderly. Of note, in accordance with neuro-imaging findings reported in the present review, preliminary clinical findings suggest the usefulness of MM in ADHD (Zylowska et al. 2008) and some authors have speculated that, by dampening the reduction in grey matter volume in cerebral areas related to attention, such as the putamen, MM might offer protection from cognitive decline usually associated with age (Pagnoni \& Cekic, 2007). In addition, future research is needed to explore whether and to what extent MM practice could prevent neurodegenerative disorder such as dementia.

Also, findings observed in expert meditators suggesting that thicker grey matter in cerebral regions associated with pain sensitivity was positively correlated with increased pain tolerance points to the notion that attending non-judgmentally to unpleasant sensations, as MM explicitly suggest, could play an important function into the reduction of such unpleasant sensations themselves (Grant et al. 2010). Indeed, as Grant et al. (2010) point out, chronic pain is usually associated with thinner rather than with thicker grey matter in some of these brain regions, suggesting that one problem in chronic pain could be not (or not only) the pain itself, but rather the 'turning away' the attention from pain that, in turn, could increase the experience of pain. Accordingly, although available evidence is still limited so far, on the basis of current findings we underscore that further longitudinal research aimed at assessing both clinical and neuro-imaging correlates of MM, possibly within the context of a single experimental design, is warranted to replicate and extend current evidence about the role that MM could play into the treatment and the prevention of several disease conditions as well as about the underlying neurobiological changes.

A. Chiesa ${ }^{\mathbf{1}^{*}}, \mathbf{P}$. Brambilla $^{\mathbf{2 , 3}}$ and A. Serretti ${ }^{1}$
${ }^{1}$ Institute of Psychiatry, University of Bologna, Italy
${ }^{2}$ Inter-University Centre for Behavioural Neurosciences
(ICBN), University of Verona, Verona and DPMSC,
Section of Psychiatry, University of Udine, Udine, Italy
${ }^{3}$ Scientific Institute 'E. Medea', Udine, Italy

\section{References}

Baerentsen KB, Hartvig NV, Stodkilde-Jorgensen H, Mammen J (2001). Onset of meditation explored with fMRI. Neuroimage 13, 297.

Bellani M, Baiano P, Brambilla P (2010). Brain anatomy of major depression. Focus on hippocampus. Epidemiologia and Psichiatria Sociale 19, 298-301.

Bellani M, Marzi CA, Brambilla P (2009). Interhemispheric communication in schizophrenia. Epidemiologia e Psichiatria Sociale 18, 19-22.

Chambers R, Gullone E, Allen NB (2009). Mindful emotion regulation: an integrative review. Clinical Psychology Review 29, 560-572.

Chiesa A, Brambilla P, Serretti A (2010). Functional neural correlates of Mindfulness meditations, psychotherapy, pharmacotherapy and placebo: is there a link? Acta Neuropsychiatrica 22, 104-117.

Chiesa A, Malinowski P (2010). Mindfulness based approaches: are they all the same? Journal of Clinical Psychology 2011 Jan 19. doi: 10.002/jclp.20776. [Epub ahead of print].

Chiesa A, Serretti A (2010). A systematic review of neurobiological and clinical features of mindfulness meditations. Psychological Medicine 40, 1239-1252.

DeRubeis RJ, Siegle GJ, Hollon SD (2008). Cognitive therapy versus medication for depression: treatment outcomes and neural mechanisms. Nature Reviews 9, 788-796.

Farb NA, Anderson AK, Mayberg H, Bean J, McKeon D, Segal ZV (2010). Minding one's emotions: mindfulness training alters the neural expression of sadness. Emotion (Washington, DC) 10, 25-33.

Farb NA, Segal ZV, Mayberg HS, Bean J, McKeon D, Fatima Z, Anderson AK (2007). Attending to the present: mindfulness meditation reveals distinct neural modes of self reference. Social Cognitive and Affective Neuroscience 2, 313-322.

Goldin PR, Gross JJ (2010). Effects of mindfulness-based stress reduction (MBSR) on emotion regulation in social anxiety disorder. Emotion (Washington, DC) 10, 83-91.

Grant JA, Courtemanche J, Duerden EG, Duncan GH, Rainville P (2010). Cortical thickness and pain sensitivity in Zen meditators. Emotion (Washington, DC) 10, 43-53.

Hölzel BK, Carmody J, Evans KC, Hoge EA, Dusek JA, Morgan L, Pitman RK, Lazar SW (2010). Stress reduction correlates with structural changes in the amygdala. Social and Cognitive Affective Neuroscience 5, 11-17. 
Hölzel BK, Ott U, Gard T, Hempel H, Weygandt M, Morgen K, Vaitl D (2008). Investigation of mindfulness meditation practitioners with voxel-based morphometry. Social and Cognitive Affective Neuroscience 3, 55-61.

Hölzel BK, Ott U, Hempel H, Hackl A, Wolf K, Stark R, Vaitl D (2007). Differential engagement of anterior cingulate and adjacent medial frontal cortex in adept meditators and non-meditators. Neuroscience Letters 421, 16-21.

Kozasa EH, Radvany J, Barreiros MA, Leite JR, Amaro E Jr (2008). Preliminary functional magnetic resonance imaging Stroop task results before and after a Zen meditation retreat. Psychiatry and Clinical Neuroscience 62, 366.

Lazar SW, Kerr CE, Wasserman RH, Gray JR, Greve DN, Treadway MT, McGarvey M, Quinn BT, Dusek JA, Benson H, Rauch SL, Moore CI, Fischl B (2005).

Meditation experience is associated with increased cortical thickness. Neuroreport 16, 1893-1897.
Pagnoni G, Cekic M (2007). Age effects on gray matter volume and attentional performance in Zen meditation. Neurobiology of Aging 28, 1623-1627.

Pagnoni G, Cekic M, Guo Y (2008). “Thinking about Not-Thinking": neural correlates of conceptual processing during Zen meditation. PLoS Medicine 3, e3083.

Vestergaard-Poulsen P, van Beek M, Skewes J, Bjarkam CR, Stubberup M, Bertelsen J, Roepstorff A (2009). Long-term meditation is associated with increased gray matter density in the brain stem. Neuroreport 20, 170-174.

Zylowska L, Ackerman DL, Yang MH, Futrell JL, Horton NL, Hale TS, Pataki C, Smalley SL (2008). Mindfulness meditation training in adults and adolescents with ADHD: a feasibility study. Journal of attention disorder 11, 737-746. 